\title{
Ureteral Stenting Following Uncomplicated Ureteroscopy for Ureteric Stones: A Randomized Controlled Trial
}

\author{
Ismaeel Aghaways' ${ }^{1}$, Sarwar N. Mahmood', Rawa H. Ghareeb2, Farhad K. Qadir ${ }^{3}$, \\ Fahmi H. Kakamad4 \\ ${ }^{1}$ Department of Surgery, Faculty of Medical Sciences, School of Medicine, University of Sulaymaniyah, \\ Sulaymaniyah, Iraq \\ ${ }^{2}$ Department of Urology, Sulaymaniyah Surgical Teaching Hospital, Sulaymaniyah, Iraq \\ ${ }^{3}$ Kalar hospital, Sulaymaniyah, Iraq \\ ${ }^{4}$ Department of Cardiothoracic Surgery, Sulaymaniyah Surgical Teaching Hospital, Sulaymaniyah, Iraq \\ Email: "dr.rawa@yahoo.com
}

Received 3 January 2016; accepted 14 February 2016; published 17 February 2016

Copyright (C) 2016 by authors and Scientific Research Publishing Inc.

This work is licensed under the Creative Commons Attribution International License (CC BY).

http://creativecommons.org/licenses/by/4.0/

\section{(c) (i) Open Access}

\begin{abstract}
Objective: The objective is to assess the benefits and adverse effects of routine ureteral stenting after uncomplicated ureteroscopic lithotripsy. Material and Methods: Sixty patients with ureteric calculi amenable to ureteroscopic lithotripsy were randomized to an unstented (30 patients) or a stented (30 patients) treatment group, standard ureteroscopic lithotripsy done using 8 French semirigid ureteroscope, and pneumatic lithotripter used to fragment the stones. They were followed up for postoperative flank pain, lower urinary tract symptoms (LUTS) and hematuria. Results: There was no significant difference in the mean age (stenting 37.8 year and 33.5 year unstenting) of patients, gender and stone size in both groups. No significant difference in the mean flank pain within 3 days postoperative, while at day 14 postoperative flank pain for stenting group was significant $(P=0.03)$. Dysuria and urgency were high for stenting group $(P=0.002$ and 0.011). Hematuria within 3 and 14 days was higher in the stenting group. Conclusion: After uncomplicated ureteroscopy, stents can be safely omitted. Unstented patients have significantly fewer LUTS, haematuria and flank pain.
\end{abstract}

\section{Keywords}

Ureteroscopy, Ureteral Stenting, Stone, Postoperative Complications

\footnotetext{
"Corresponding author.
} 


\section{Introduction}

Urinary stone disease is the third most common affliction of the urinary tract [1]. It affects $5 \%-12 \%$ of the population during their lifetime. Males are affected as twice as female [2]. Kidney stones are categorized as either staghorn (filling numerous major and minor calices) or non-staghorn. Non-staghorn stones are described as calyceal or pelvic in location. Majority of them are calcium stones accounting for approximately $80 \%$ of all of these stones, uric acid (UA) about $9 \%$, and struvite approximately $10 \%$, leaving only $1 \%$ for all the rest (cystine, drug stones, ammonium acid urate) [3]. Renal stones may be asymptomatic and detected only incidentally or thy associate with pain, obstruction and infection [1].

Technological developments have drastically changed the management of ureteric calculi in the last two decades [4]. In 1989 a new generation of "semirigid" ureteroscopes was developed and contained fiber optics rather than a rod-lens system. [5]

Stone disintegration through ureteroscope can be achieved with in situ lithotripsy. The spectrum of lithotripters includes ultrasonic lithotripsy, electro-hydraulic lithotripsy, pneumatic lithotripsy, and laser lithotripsy. Stone fragments $<5 \mathrm{~mm}$ in diameter are the best retrieved with a grasper or basket [6].

Complications during ureteroscopy have decreased over the past 20 years because of improvements in ureteroscopes, ancillary devices, intracorporeal lithotripters, and surgical skills [7]. The miniaturization of the instruments allows easier access within the ureter without prior dilatation in more than $50 \%$ of the patients and easier approach of the proximal ureter [8].

Stent positioning as a routine part of the postoperative care after uncomplicated ureteroscopy remained a matter of debate [9]. The value of stenting is the prevention of ureteral obstruction and renal colic, which may develop following stone retrieval, it may aid in the passage of stone fragments and prevent delayed ureteral stricture, but its use may be accompanied by troublesome urinary symptoms [10]-[12]. The complications are common, such as lower urinary tract symptoms, infection, migration, breakage, encrustation and stone formation [13].

Tang et al. evaluated the outcome of stenting after uncomplicated ureteroscopy in a systematic review and meta-analysis that included 14 randomized controlled trials; they concluded that the place of stenting after uncomplicated ureteroscopy remained unclear due to marked clinical heterogeneity and various qualities of the included trials [14].

However routine placement of a ureteral stent following uncomplicated Ureteroscopic removal of distal ureteral stones was not necessary by some authors [15].

The aim of this randomized clinical trial is to assess the need for routine placement of ureteral stent after uncomplicated ureteroscopy and to assess the outcomes among stented and unstented patients.

\section{Materials and Methods}

From July 2013 to July 2014, 60 patients with ureteric stones underwent ureteroscopic lithotripsy at a single center. They were randomly allocated into a stented and an unstented group after gaining acceptance of ethical committee approval of our center. Patients with stone of $>2 \mathrm{~cm}$, solitary kidney and patients with major ureteric injury during the procedure that required stenting were excluded in this study.

Ureteroscopic procedures were performed without ureteral dilatation under spinal anesthesia in a standard fashion with semirigid (8 French) (Karl Storz) ureteroscopes after receiving prophylactic antibiotic according to the local hospital guidelines which were continued 5 days postoperatively orally. The stones were fragmented in to nearly less than $3 \mathrm{~mm}$ in size using pneumatic lithotripter by comparison of the gravels to the tip of probe of lithotripter. Double pigtail 6 French ureteral stents were inserted for the stented group. The ureteral stents were removed 2 weeks later.

Clinical and intraoperative variables, including indications, stone burden and stone location were recorded. Total stone burden was assessed by preoperative radiographs including: Kidney ureter bladder (KUB), Intravenous pyelography (IVP) with or without Computed tomography.

Postoperative symptoms including hematuria and flank pain were assessed on $3^{\text {rd }}$ and $14^{\text {th }}$ postoperative day. Pain was evaluated by Visual Analog Scale (VAS) which is a subjective measure of pain. It was classified into no pain (VAS $=0$ ), mild (VAS $=1-4$ ), moderate (VAS $=5-7$ ) and severe (VAS = 8 - 10). Hematuria was assessed by urinalysis at each session of follow up. Lower urinary tract symptoms like dysuria and urgency were assessed on $3^{\text {rd }}$ day postoperative day by a questionnaire. All patients were followed up for 3 months for late 
complications like ureteric stricture formation.

For statistical analysis independent sample $t$ test for quantitative variables, Chi-square test for qualitative variables and $\mathrm{P}$ value $<0.05$ was considered statistically significant.

\section{Results}

The difference in age, gender, laterality, stone number, stone size and preoperative pain score between stenting group and non-stenting group was statistically not significant $\mathrm{P}>0.05$ (see Table 1).

Postoperative symptoms outlined in Table 2. Flank pain at $3^{\text {rd }}$ day was nearly the same between the groups, while at $14^{\text {th }}$ day it was higher in the stented group and statistically significant (P value 0.038 ). Hematuria was also higher among stented group at $3^{\text {rd }}$ and $14^{\text {th }}$ postoperative day $(0.02$ and 0.001$)$ respectively.

Regarding irritative LUTS like dysuria and urgency, they were significantly higher among stented group (90\% and $66.7 \%$ ) versus (53.3\% and 33.3\%) in unstented groups.

Two patients among unstended groups readmitted to the emergency unit at $7^{\text {th }}$ and $10^{\text {th }}$ postoperative day, the aforementioned one presented with intractable flank pain whom didn't respond to conservative measures, second session ureteroscopy was done for him successfully without putting ureteral stent, the other one presented with signs and symptoms of pyelonephritis which responded well to medical treatments.

During 3 month follow up no ureteric stricture formation found in both groups.

\section{Discussion}

With the relatively recent development of modern ureteroscopes, it may be less traumatic due to their decrease caliber size, improved flexibility and tapered tips and also with more effective intracorporeal lithotripsy devices it is now possible to perform ureteroscopy in most patients without ureteral dilatation [16]. In our study, we performed the procedure for all patients without ureteral dilation.

The etiology of early postoperative flank pain is not well understood and likely to be multifactorial including; extravasation of irrigating fluid, manipulation of the collecting system and distal ureteral edema leading to temporary ureteral obstruction. In our study there is no significant difference in the early postoperative flank pain between the groups (P value 0.301), this is consistent with what has been observed by Hussein et al. [17] in contrast with others [9] [18] that they showed lesser postoperative flank pain in stented patients, while late postoperative flank pain is found to be statistically significant in this study (P value 0.038 ), this is similar to the results of other investigators [19].

\begin{tabular}{cccc}
\hline \multicolumn{2}{l}{ Table 1. General characteristics of the patients. } & & \\
\hline characteristics & Stenting & unstenting & P-value \\
\hline Age/Yr & $37.8+11.1$ & $33.5+11.3$ & 0.127 \\
Gender/No. \& $\%$ & & \\
Male & & $18(60.0)$ & 0.273 \\
Female & $22(73.3)$ & $12(40.0)$ & \\
Laterality & $8(26.7)$ & & \\
Right & $12(40.0)$ & $16(53.3)$ & 0.301 \\
Left & $18(60.0)$ & $14(46.7)$ & \\
Size/mm & & & \\
$6-10$ & $19(63.3)$ & $23(76.6)$ & 0.090 \\
$11-15$ & $10(33.3)$ & $3(10.0)$ & \\
$16-20$ & $1(3.3)$ & $4(13.4)$ & \\
Stone No. & & & \\
One stone & $29(96.7)$ & $4(13.4)$ & 0.161 \\
Two stone & $1(3.3)$ & & \\
Visual analog pain & & & \\
scores & $0(0.0)$ & $0(0.0)$ & \\
No & $0(0.0)$ & $17(56.7)$ & 0.626 \\
Mild & $24(80.0)$ & $13(43.3)$ & \\
Moderate & $6(20.0)$ & & \\
Severe & &
\end{tabular}


Table 2. General characteristics of the patients.

\begin{tabular}{|c|c|c|c|}
\hline Characteristics & Stenting & Unstenting & P-value \\
\hline $\begin{array}{l}\text { Visual analog pain } \\
\text { scores at day } 3 \\
\text { No pain } \\
\text { Mild } \\
\text { Moderate } \\
\text { Severe }\end{array}$ & $\begin{array}{c}0(0.0) \\
29(96.7) \\
1(3.3) \\
0(0.0)\end{array}$ & $\begin{array}{c}0(0.0) \\
27(90.0) \\
3(10.0) \\
0(0.0)\end{array}$ & 0.301 \\
\hline $\begin{array}{c}\text { Visual analog pain } \\
\text { scores at day } 14 \\
\text { No } \\
\text { Mild } \\
\text { Moderate } \\
\text { Severe }\end{array}$ & $\begin{array}{c}0(0.0) \\
27(90.0) \\
3(10.0) \\
0(0.0)\end{array}$ & $\begin{array}{c}5(16.7) \\
20(66.6) \\
5(16.7) \\
0(0.0)\end{array}$ & 0.038 \\
\hline $\begin{array}{c}\text { Postoperative dysuria } \\
\text { Yes } \\
\text { No }\end{array}$ & $\begin{array}{c}27(90.0) \\
3(10.0)\end{array}$ & $\begin{array}{l}16 \text { (53.3) } \\
14(46.7)\end{array}$ & 0.002 \\
\hline $\begin{array}{c}\text { Postoperative urgency } \\
\text { Yes } \\
\text { No }\end{array}$ & $\begin{array}{l}20(66.7) \\
10(33.3)\end{array}$ & $\begin{array}{l}10(33.3) \\
20(66.7)\end{array}$ & 0.011 \\
\hline $\begin{array}{c}\text { Postoperative hematuri } \\
\text { at day } 3 \\
\text { Yes } \\
\text { No }\end{array}$ & $\begin{array}{c}28(93.3) \\
2(6.7)\end{array}$ & $\begin{array}{c}21(70.0) \\
9(30.0)\end{array}$ & 0.020 \\
\hline $\begin{array}{l}\text { Postoperative hematuri } \\
\text { at day } 14 \\
\text { Yes } \\
\text { No }\end{array}$ & $\begin{array}{l}16(53.3) \\
14(46.7)\end{array}$ & $\begin{array}{c}2(6.7) \\
28(93.3)\end{array}$ & 0.001 \\
\hline
\end{tabular}

Irritative lower urinary tract symptoms like dysuria and urgency were higher in our study for stented group and it is of statistical significance (p value 0.002 and 0.011) respectively, this is supported by results of Srivastava et al. [20] in contrary to the result of Yong Xu et al. [21] in which the difference was not shown to be significant in terms of urgency. Our result could be explained by the fact that patients with stents are exposed to numerous potential stent complications such as migration, infection.

Hematuria was another early and late postoperative complication which has been found to be higher in the stented than unstented group patients and it is found to be statistically significant which also seen by Hussein et al. [17] On the contrary postoperative hematuria was not significant in Damiano et al. [18] It may be due to urothelial injury during excessive manipulation of the ureter, in addition to that ureteral stent by itself can act as a foreign body and causing erosion of urinary tract that lead to hematuria. In the absence of an absolute indication to place a ureteric stent after ureteroscopy, such as a solitary kidney, pyonephrosis, transplanted kidney, ureteric perforation and large residual stone burden, there are little evidence to suggest that routine stent placement has any beneficial effect in terms of length of hospital stay, risk of re-hospitalization, postoperative pain, stone-free rates or risk of delayed ureteric stricture formation [14]. The finding of this study is against routine placement of ureteral stent following uncomplicated ureteroscopy.

There are limitations regarding this study. First: the sample size is small for a clinical trial aiming to solve the long lasting controversy regarding routine placement of ureteral stent following uncomplicated ureteroscopy. Second: missing data regarding some important issues like cost-effectiveness between the groups and some lower urinary tract symptoms.

\section{Conclusion}

With modern ureteroscope, ureteroscopy can be performed without ureteral dilatation. After uncomplicated ure- 
teroscopy, stents can be safely omitted. Unstented patients have significantly fewer lower urinary symptoms, haematuria and flank pain. Further studies with larger sample size are recommended.

\section{References}

[1] Pearle, M.S., Calhoun, E.A. and Curhan, G.C. (2005) Urologic Diseases in America Project: Urolithiasis. The Journal of Urology, 173, 848-857. http://dx.doi.org/10.1097/01.ju.0000152082.14384.d7

[2] Stamatelou, K.K., Francis, M.E., Jones, C.A., et al. (2003) Time Trends in Reported Prevalence of Kidney Stones in the United States: 1976-1994. Kidney International, 63, 1817-1823. http://dx.doi.org/10.1046/j.1523-1755.2003.00917.x

[3] Evan, A.P. (2010) Physiopathology and Etiology of Stone Formation in the Kidney and the Urinary Tract. Pediatric Nephrology (Berlin, Germany), 25, 831-841. http://dx.doi.org/10.1007/s00467-009-1116-y

[4] Singh, H., Tandon, V., Dwivedi, U.S., et al. (2003) Management of Proximal Ureteral Stones—Comparison of Outpatient Ureterolithotripsy with In-Situ Shock Wave Lithotripsy (SWL). Indian Journal of Urology, 20, 23-27.

[5] Dretler, S.P. and Cho, G. (1989) Semirigid Ureteroscopy. A New Genre. The Journal of Urology, 141, 1314-1316.

[6] Harmon, W.J., Sershon, P.D., Blute, M.L., et al. (1997) Ureteroscopy: Current Practice and Long-Term Complications. The Journal of Urology, 157, 28-32. http://dx.doi.org/10.1097/00005392-199701000-00009

[7] Daneshmand, S., Quek, M.D. and Huffman, J.L. (2003) Endoscopic Management of Upper Urinary Tract Transitional Cell Carcinoma: Long-Term Experience. Cancer, 98, 55-60. http://dx.doi.org/10.1002/cncr.11446

[8] Puppo, P., Riccioti, G., Bozzo, W., et al. (1999) Primary Endoscopic Treatment of Ureteric Calculi. A Review of 378 Cases. European Urology, 36, 48-52. http://dx.doi.org/10.1159/000019926

[9] Hosking, D.H., McColm, S.E. and Smith, W.E. (1999) Is Stenting Following Ureteroscopy for Removal of Distal Ureteral Calculi Necessary? The Journal of Urology, 161, 48-50. http://dx.doi.org/10.1016/S0022-5347(01)62058-5

[10] Rayan, P.C., Lennon, G.M., McLean, P.A., et al. (1994) The Effects of Acute and Chronic JJ Stent Placement on Upper Urinary Tract Motility and Calculus Transit. British Journal of Urology, 74, 434. http://dx.doi.org/10.1111/j.1464-410X.1994.tb00418.x

[11] Joshi, H.B., Newns, N., Stainthorpe, A., et al. (2003) Ureteral Stent Symptom Questionnaire: Development and Validation of a Multidimensional Quality of Life Measure. The Journal of Urology, 169, 1060. http://dx.doi.org/10.1097/01.ju.0000049198.53424.1d

[12] Duvdevani, M., Chew, B.H. and Denstedt, J.D. (2006) Minimizing Symptoms in Patients with Ureteric Stents. Current Opinion in Urology, 16, 77. http://dx.doi.org/10.1097/01.mou.0000193375.29942.0f

[13] Singh, I., Gupta, N.P., Hemal, A.K., et al. (2001) Severely Encrusted Polyurethane Ureteral Stents: Management and Analysis of Potential Risk Factors. Urology, 58, 526. http://dx.doi.org/10.1016/S0090-4295(01)01317-6

[14] Tang, L., Gao, X., Xu, B., et al. (2011) Placement of Ureteral Stent after Uncomplicated Ureteroscopy: Do We Really Need It? Urology, 78, 1248-1256. http://dx.doi.org/10.1016/j.urology.2011.05.004

[15] El Harrech, Y., Abakka, N., El Anzaoui, J., et al. (2014) Ureteral Stenting after Uncomplicated Ureteroscopy for Distal Ureteral Stones: A Randomized, Controlled Trial. Minimally Invasive Surgery, 2014, Article ID: 892890. http://dx.doi.org/10.1155/2014/892890

[16] Foreman, D., Plagakis, S. and Fuller, A.T. (2014) Should We Routinely Stent after Ureteropyeloscopy? BJU International, 114, 6-8. http://dx.doi.org/10.1111/bju.12708

[17] Hussein, A., Rifaat, E., Zaki, A., et al. (2006) Stenting versus Non-Stenting after Non-Complicated Ureteroscopic Manipulation of Stones in Bilharzial Ureters. IJU, 13, 886-890.

[18] Damiano, R., Autorino, R., Esposito, C., et al. (2004) Stent Positioning after Ureteroscopy for Urinary Calculi: The Question Is Still Open. European Urology, 46, 381-388. http://dx.doi.org/10.1016/j.eururo.2004.04.004

[19] Borboroglu, P.G., Amling, C.L., Schenkman, N.S., et al. (2001) Ureteral Stenting after Ureteroscopy for Distal Ureteral Calculi: A Multi-Istitutional Prospective Randomized Controlled Study Assessing Pain, Outcomes and Complications. The Journal of Urology, 166, 1651-1657. http://dx.doi.org/10.1016/S0022-5347(05)65646-7

[20] Srivastava, A., Gupta, R., Kumar, A., Kapoor, R. and Mandhani, A. (2003) Routine Stenting after Ureteroscopy for distal Ureteral Calculi Is Unnecessary: Results of a Randomized Controlled Trial. Journal of Endourology, 17, 871-814. http://dx.doi.org/10.1089/089277903772036172

[21] Xu, Y., Wei, Q. and Liu, L.R. (2009) A Prospective Randomized Trial Comparing Non-Stented versus Routine Stented Ureteroscopic Holmium Laser Lithotripsy. Saudi Medical Journal, 30, 1276. 


\section{Abbreviations and Acronyms}

LUTS = Lower Urinary tract Symptoms

VAS $=$ Visual Analog Scale for pain assessment

$\mathrm{UA}=$ Uric Acid 